\title{
Influence of Structural Characteristics on the Mechanical Properties of FDM Printed PLA Material
}

\author{
Stefan Szczepanik* ${ }^{*}$, Piotr Nikiel ${ }_{\mathbb{C}}$ \\ AGH University of Science and Technology, Faculty of Metals Engineering and Industrial Computer Science, \\ Mickiewicza 30 Ave., 30059 Krakow, Poland \\ *e-mail: szczepan@metal.agh.edu.pl
}

(C) 2020 Authors. This is an open access publication, which can be used, distributed and reproduced in any medium according to the Creative Commons CC-BY 4.0 License requiring that the original work has been properly cited.

Received: 11 November 2019/Accepted: 29 January 2020/ Published online: 30 March 2020

This article is published with open access at AGH University of Science and Technology Press

\begin{abstract}
The present study reports on the influence of printing process parameters, architecture, raster, infill orientation and filling on the density, macrostructure, and mechanical properties, including impact resistance, of biodegradable polymer parts fabricated in polylactide (PLA) on a desktop printer. It complements and considers phenomenologically the results of recently published similar studies, including the use of recycled filament. In our study, complex mechanical properties for the samples printed at the same time on a Replicator 2 printer were investigated. Three samples were printed for each test. Full mechanical characteristics (tensile, compression and bend strengths and impact resistance) of the printed PLA material are reported. This is the novelty in comparison to other studies, where the samples test were printed individually or in a series for each test. The shape and thickness of the layered macrostructure, the presence of holes inside the layers, the number of shell perimeters and the fill density all influenced the tensile properties of the printed materials. These results show the possibility of printing with a 0.3 , i.e. shorter printing time than $0.1,0.15$ and $0.18 \mathrm{~mm}$ layer thicknesses also reported, without significant decrease in mechanical properties. It is interesting to note that the compressive strengths, the yield of 70-80 MPa and a UTS 113-120 MPa for the printed material with a fill density of $94-96 \%$ are comparable with those of aluminum.
\end{abstract}

\section{Keywords:}

additive manufacturing, polymer and plastics, polylactide, mechanical properties

\section{INTRODUCTION}

The relation between mechanical properties and process parameters (gap, raster width and angle) for polycarbonate parts produced by Stratasys FDM Fused Deposition Modeling (FDM) Technology has been considered e.g. by Masood [1] and Masood et al. [2] and the results compared with moulded and extruded parts. Bellini and Güçeri [3] investigated the mechanical properties of acrylonitrile butadiene styrene (ABS) parts fabricated by FDM and proposed how building direction and path determine the mechanical properties. Novakova-Marcincinova and Novak-Marcincin [4] tensile tested ABS material produced with different geometric parameters by FDM rapid prototyping technology. Smith and Dean's [5] study focused on the determination of tensile strength, yield strength and modulus of elasticity for polycarbonate material produced by fused deposition modeling with different values of build orientation.
Identification of optimum values for the main geometric parameters of the FDM printing process to achieve minimum cost was investigated by Durgun and Ertan [6].

Several research teams [7-10] have investigated printing by the biodegradable polylactide (PLA) and reported on the resultant mechanical properties. Lanzotti et al. [7] reported the effect of process parameters on tensile properties, including a decrease in strength as the infill orientation approaches 90 degrees and an increase as the perimeters increase. Grasso et al. [8] went on to show a strong correlation between stiffness and strength with infill orientation and temperature. They considered the deformed geometry of the filament approaching the glass transition region of the polymer according to the deposition orientation. Letcher and Waytashek [9] printed each specimen individually at the center of the printing bed and accordingly obtained less scatter in the properties investigated, including fatigue. Anderson [10] additionally considered the use of recycled 
filament and concluded that, overall, the mechanical properties of 3D printed specimens from recycled PLA filament were similar to virgin properties, but the scatter was larger.

The present study reports on the influence of the printing process parameters, architecture, raster, infill orientation and filling on the density, macrostructure, and mechanical properties, including impact resistance, of printed PLA specimens and compares and contrasts the new results with those which have been published previously. Full mechanical characteristics, tensile, compression and bend strengths and impact resistance, of the printed PLA material are reported.

\section{MATERIALS AND TESTING METHODS}

The PLA Fiberlogy filament used for printing test specimens has the following tensile properties: tensile strength UTS 55.4 MPa and yield stress YS $45 \mathrm{MPa}$. Samples' design for tensile, compressive, bend and impact testing are illustrated in Figure 1 and their detailed characteristics in Table 1. Test samples were marked as follows: I - series, no., layer thickness [mm], fill volume [\%], and architecture / structure. All samples were fabricated on a Replicator 2 printer from red PLA polymer at the CadXpert Company in Krakow. a)

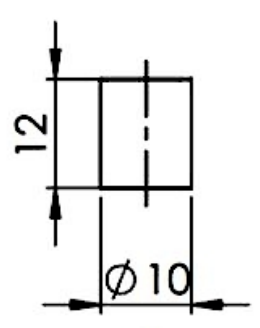

c)

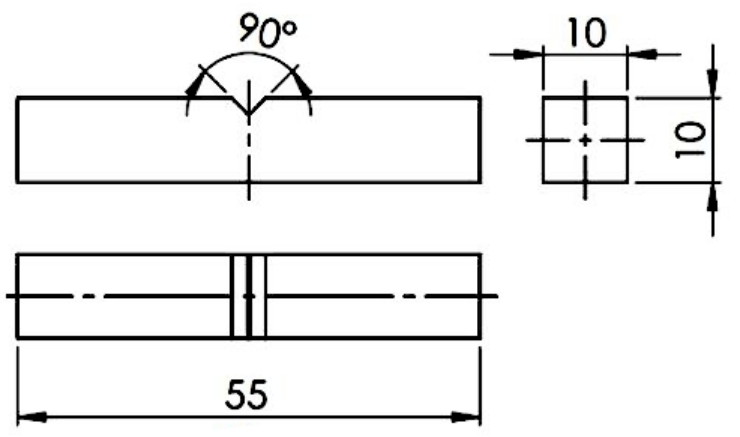

b)

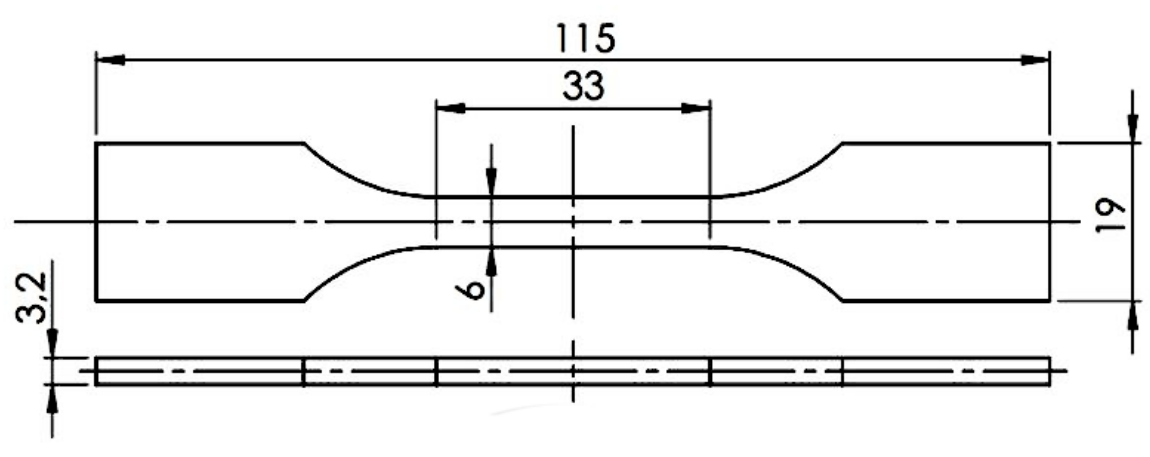

d)

Fig. 1. Drawings of the test samples (all dimensions in millimeters)

Table 1

Specifications of the samples: printed layer thickness, filling and specimen architecture

\begin{tabular}{|c|c|c|c|c|}
\hline Series & No. of set samples & $\begin{array}{c}\text { Layer } \\
\text { thickness, } \\
\text { mm } \\
\end{array}$ & $\begin{array}{c}\text { Filling, } \\
\%\end{array}$ & Architecture of filled material \\
\hline \multirow{4}{*}{$\mathrm{I}$} & 1 & 0.1 & \multirow{2}{*}{50} & \\
\hline & 2 & 0.3 & & \\
\hline & 3 & 0.1 & \multirow{2}{*}{100} & \\
\hline & 4 & 0.3 & & \\
\hline \multirow{4}{*}{ II } & 5 & 0.1 & \multirow{2}{*}{50} & \\
\hline & 6 & 0.3 & & \\
\hline & 7 & 0.1 & \multirow{2}{*}{100} & \\
\hline & 8 & 0.3 & & \\
\hline
\end{tabular}


Figure 2 shows the virtual arrangement for printing on the plate in the MakerBot Print program. The temperature of the printing nozzle was $215^{\circ} \mathrm{C}$, the time and material consumption are recorded in Table 2 .

Three samples were fabricated for every specimen shape, with a total of 96 . Figure 3 shows test samples printed for variant I. Mechanical properties: Young's modulus, engineering yield (tensile and compressive) and ultimate tensile stress and elongation, were determined at room temperature on an Instron 4502 machine at a rate of $5 \mathrm{~mm} /$ minute. For three point bending, the span was $48 \mathrm{~mm}$. Charpy impact resistance was determined for notched samples.

a)

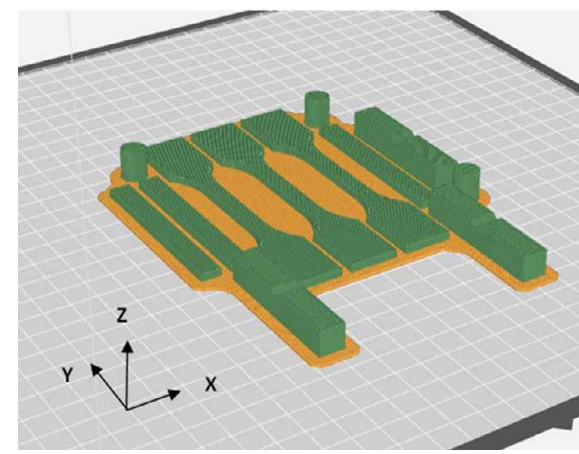

b)

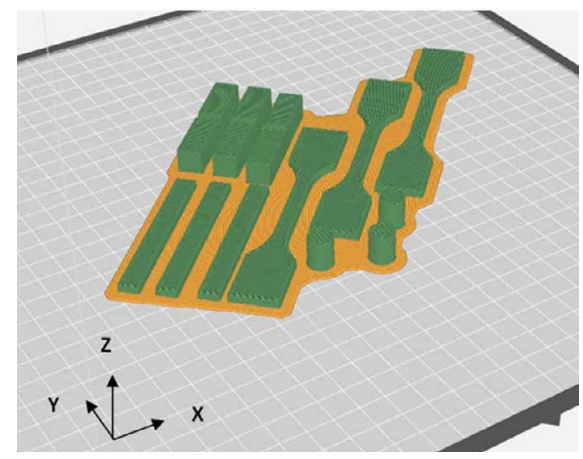

Fig. 2. Virtual arrangement for printing on the plate in the MakerBot Print program, the path of printing the sample with regard to the axis, raster orientation direction: a) $0^{\circ}$ (series I); b) $\pm 45^{\circ}$ (series II)

Table 2

Printing parameters

\begin{tabular}{|c|c|c|c|c|c|}
\hline Series & $\begin{array}{l}\text { No. of set } \\
\text { samples }\end{array}$ & $\begin{array}{c}\text { Layer } \\
\text { thickness, } \\
\text { mm }\end{array}$ & $\begin{array}{l}\text { Filling, } \\
\%\end{array}$ & $\begin{array}{c}\text { Printing } \\
\text { time, } \\
\text { h:min } \\
\end{array}$ & $\begin{array}{c}\begin{array}{c}\text { Filament } \\
\text { consumption, } \\
\text { g }\end{array} \\
\end{array}$ \\
\hline \multirow{4}{*}{ I } & 1 & 0.1 & \multirow{2}{*}{50} & 4.44 & \multirow{2}{*}{51} \\
\hline & 2 & 0.3 & & 2.55 & \\
\hline & 3 & 0.1 & \multirow{2}{*}{100} & 5.33 & \multirow{2}{*}{66} \\
\hline & 4 & 0.3 & & 3.43 & \\
\hline \multirow{4}{*}{ II } & 5 & 0.1 & \multirow{2}{*}{50} & 5.39 & \multirow{2}{*}{53} \\
\hline & 6 & 0.3 & & 3.26 & \\
\hline & 7 & 0.1 & \multirow{2}{*}{100} & 6.37 & \multirow[b]{2}{*}{69} \\
\hline & 8 & 0.3 & & 4.23 & \\
\hline
\end{tabular}

a)

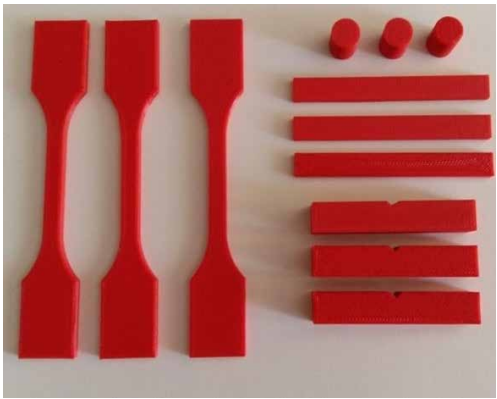

b)

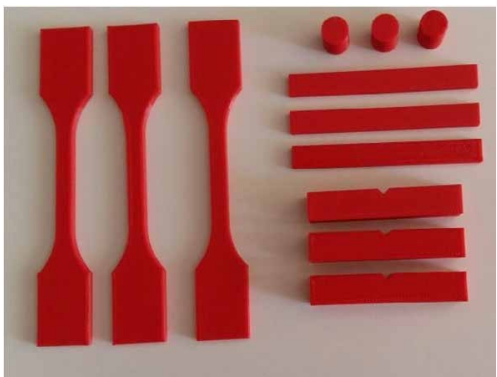

Fig. 3. Printed PLA samples: a) series $I-1$, raster orientation direction $0^{\circ}$; b) series II-1, raster orientation direction $45^{\circ}$

\section{RESULTS}

\subsection{Tensile testing}

Figure 4 presents nominal stress-nominal strain curves for different type of specimens.

a)

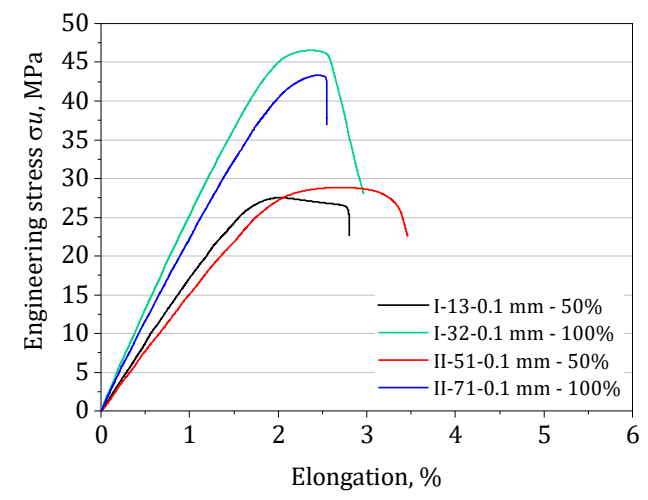

b)

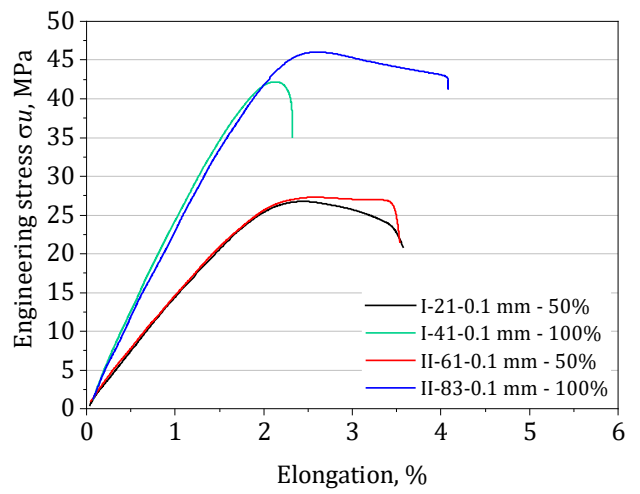

Fig. 4. Engineering stress-strain plots for $50 \%$ and $100 \%$ filling: a) $0.1 \mathrm{~mm}$; b) $0.3 \mathrm{~mm}$ layer thickness (samples were marked follows: series, no. of set samples, no. of sample, layer thickness, filling, see Table 1) 
Cracking of samples took place perpendicularly to the tensile axis after small elongations. Figure 5 collects the average values of yield and tensile strengths and Figure 6 total elongation. Error bar analysis is presented in the "Discussion" section (see. Tab. 3).

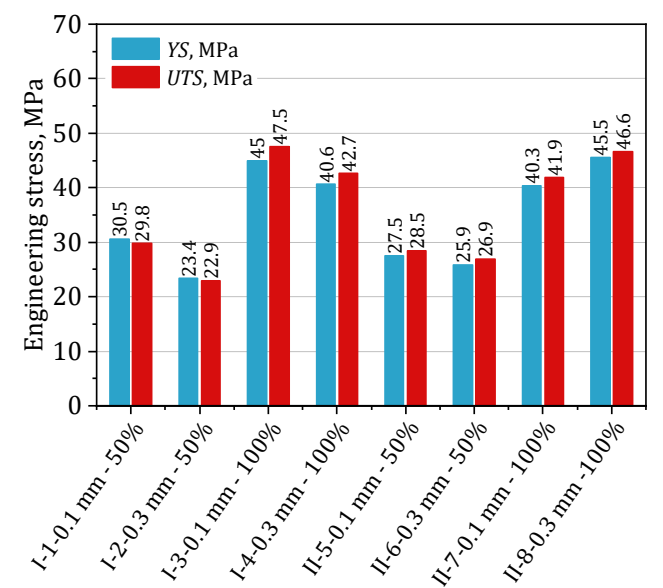

Fig. 5. Average values of yield and ultimate tensile stresses of the printed material (samples were marked: series, no. of set samples, layer thickness, filling, see Table 1)

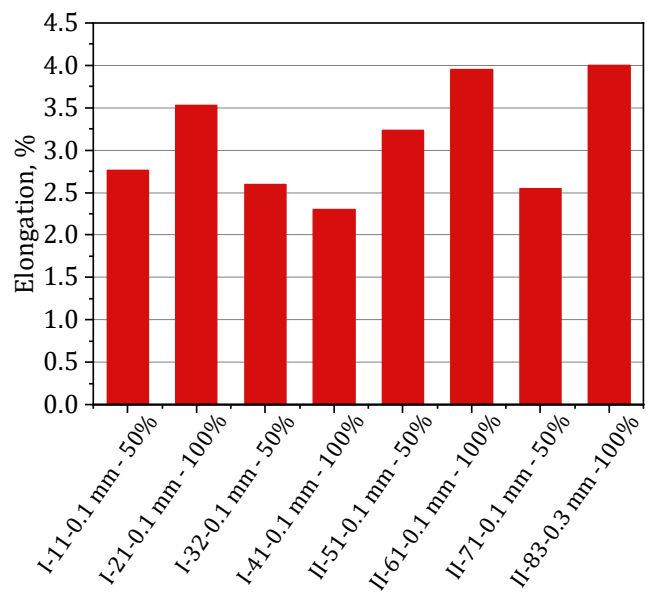

Fig. 6. Values of total tensile elongation of selected printed samples (samples were marked: series, no. sample, layer thickness, filling, see Table 1)

\subsection{Compression testing}

Figure 7 illustrates engineering compressive stress-strain plots and Figure 8 shows the samples after compression.

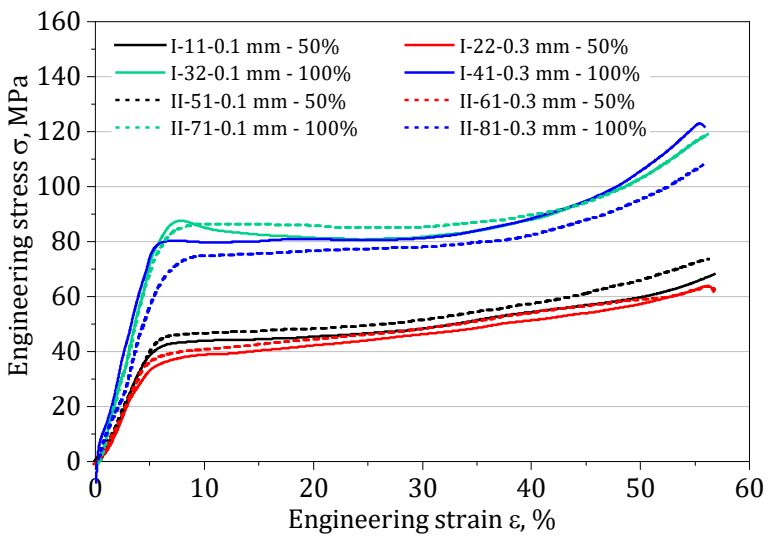

Fig. 7. Plot of engineering compressive stress-strain (samples were marked follows: series, no. of set samples, no. of sample, layer thickness, filling, see Table 1)

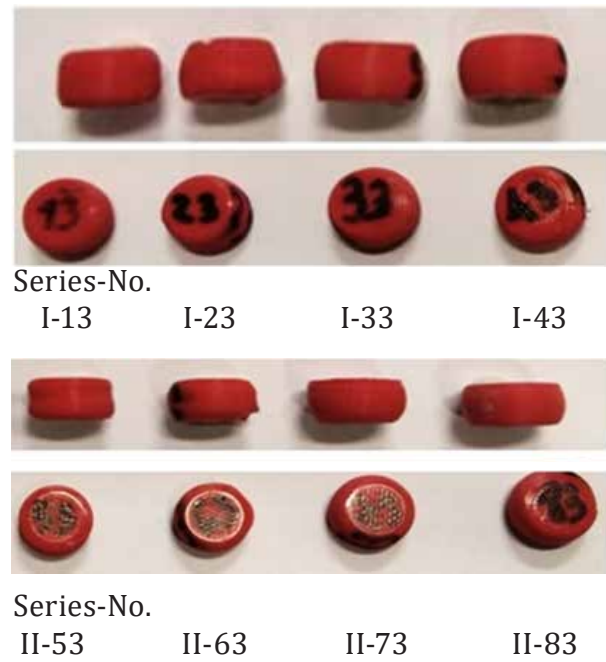

Fig. 8. Specimens after compression testing (samples were marked: series, no. samples (see Table 1)

Table 3

Mechanical properties of printed PLA materials

\begin{tabular}{|c|c|c|c|c|c|c|c|c|c|c|}
\hline \multirow{3}{*}{ No. } & \multirow{3}{*}{$\begin{array}{c}\text { Layer } \\
\text { thick-ness, } \\
\text { mm }\end{array}$} & \multirow{3}{*}{$\begin{array}{l}\text { Architecture } \\
\text { /filling }\end{array}$} & \multicolumn{7}{|c|}{ Mechanical properties } & \multirow{3}{*}{$\begin{array}{c}\text { Impact } \\
\text { resistance } \\
\mathrm{J} / \mathrm{cm}^{2}\end{array}$} \\
\hline & & & \multicolumn{3}{|c|}{ tensile } & \multicolumn{2}{|c|}{ compression } & \multicolumn{2}{|c|}{ bend } & \\
\hline & & & $\begin{array}{c}E, \\
\text { GPa }\end{array}$ & $\begin{array}{l}Y S_{0.2{ }^{\prime}} \\
\text { MPa }\end{array}$ & $\begin{array}{l}\text { UTS, } \\
\text { MPa }\end{array}$ & $\begin{array}{l}Y C_{0.2} \\
\mathrm{MPa} \\
\end{array}$ & $\begin{array}{c}C S, \\
\mathrm{MPa}\end{array}$ & $\begin{array}{l}\sigma_{b 0.2} \\
\text { MPa }\end{array}$ & $\begin{array}{c}\sigma_{b^{\prime}} \\
\mathrm{MPa}\end{array}$ & \\
\hline 1 & 0.1 & & $1.6 \pm 0.17$ & $31 \pm 3$ & $30 \pm 2$ & $41 \pm 2$ & $70 \pm 2$ & $67 \pm 3$ & $68 \pm 3$ & $0.37 \pm 0.03$ \\
\hline 2 & 0.3 & $-/ 50 \%$ & $1.4 \pm 0.06$ & $23 \pm 3$ & $23 \pm 4$ & $33 \pm 1$ & $66 \pm 1$ & $53 \pm 5$ & $55 \pm 2$ & $0.33 \pm 0.03$ \\
\hline 3 & 0.1 & & $2.5 \pm 0.04$ & $45 \pm 4$ & $48 \pm 1$ & $84 \pm 1$ & $121 \pm 3$ & $99 \pm 1$ & $102 \pm 1$ & $0.45 \pm 0.03$ \\
\hline 4 & 0.3 & $/ 100 \%$ & $2.3 \pm 0.13$ & $41 \pm 1$ & $43 \pm 1$ & $76 \pm 1$ & $121 \pm 3$ & $82 \pm 1$ & $85 \pm 2$ & $0.42 \pm 0.03$ \\
\hline 5 & 0.1 & & $1.5 \pm 0.06$ & $28 \pm 2$ & $29 \pm 2$ & $41 \pm 1$ & $73 \pm 3$ & $61 \pm 3$ & $63 \pm 4$ & $0.28 \pm 0.07$ \\
\hline 6 & 0.3 & $/ 50 \%$ & $1.4 \pm 0.09$ & $26 \pm 1$ & $27 \pm 1$ & $35 \pm 3$ & $62 \pm 10$ & $60 \pm 1$ & $65 \pm 1$ & $0.33 \pm 0.04$ \\
\hline 7 & 0.1 & & $2.1 \pm 0.19$ & $40 \pm 1$ & $42 \pm 2$ & $80 \pm 2$ & $113 \pm 3$ & $70 \pm 3$ & $77 \pm 1$ & $0.42 \pm 0.05$ \\
\hline 8 & 0.3 & $/ 100 \%$ & $2.2 \pm 0.06$ & $46 \pm 2$ & $47 \pm 2$ & $71 \pm 4$ & $113 \pm 3$ & $99 \pm 1$ & $101 \pm 4$ & $0.38 \pm 0,04$ \\
\hline
\end{tabular}


Mean strength values of compression yield strength $Y S_{0.2}$ and compression strength $C S$ are shown in Figure 9.

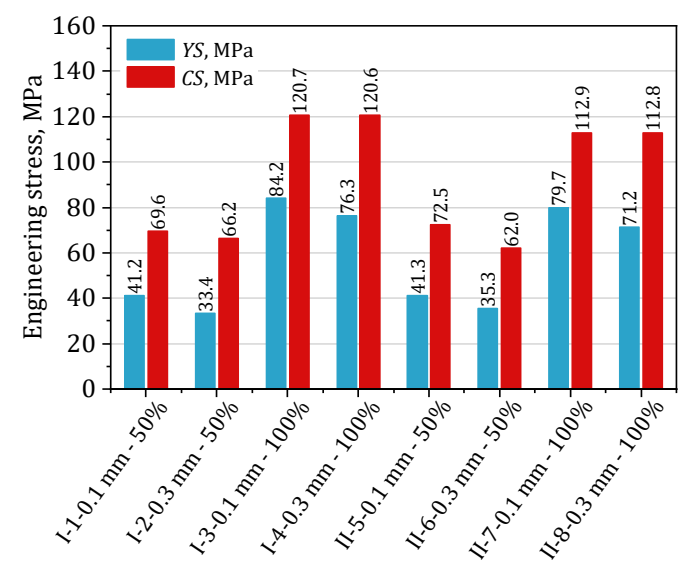

Fig. 9. Average compressive yield stress values $Y S_{0.2}$ and compression strength $C S$, for printed thicknesses 0.1 or $0.3 \mathrm{~mm}$ and filling 50 or $100 \%$ (legend: series, no. of set samples, layer thickness [mm], filling, architecture, see Figure 1)

\subsection{Bend testing}

Figure 10 shows plots of bending stress versus ram displacement, and Figure 11 summarizes the yield and (nominal) bend strength data. Fractographs are shown in Figure 12. Holes between layers and filament changes are visible on the fracture surfaces of the printed samples.

a)

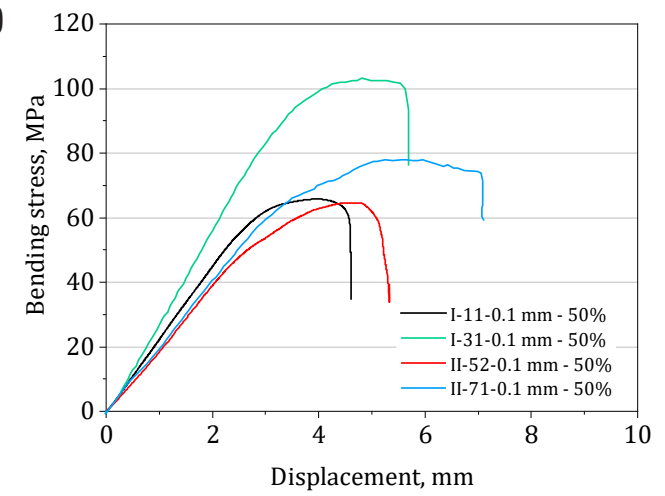

b)

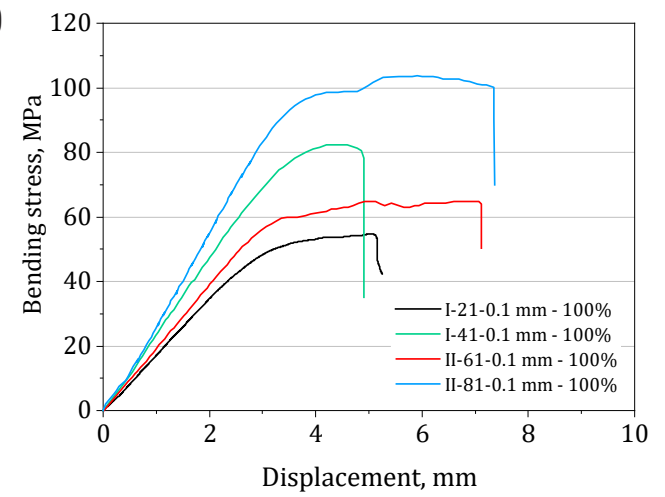

Fig. 10. Plots of bending stress vs ram displacement (samples were marked: series, no. of set samples, layer thickness, filling, see Table 1)

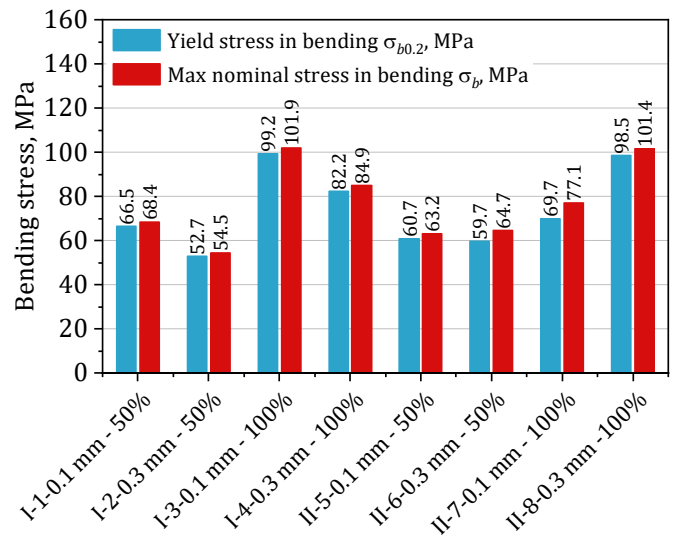

Fig. 11. Average values of the yield stress $\sigma_{b 0.2}$ and nominal bend strength $\sigma_{b}$ at failure (legend: series, no. of set samples, layer thickness, filling, see Table 1)

a)

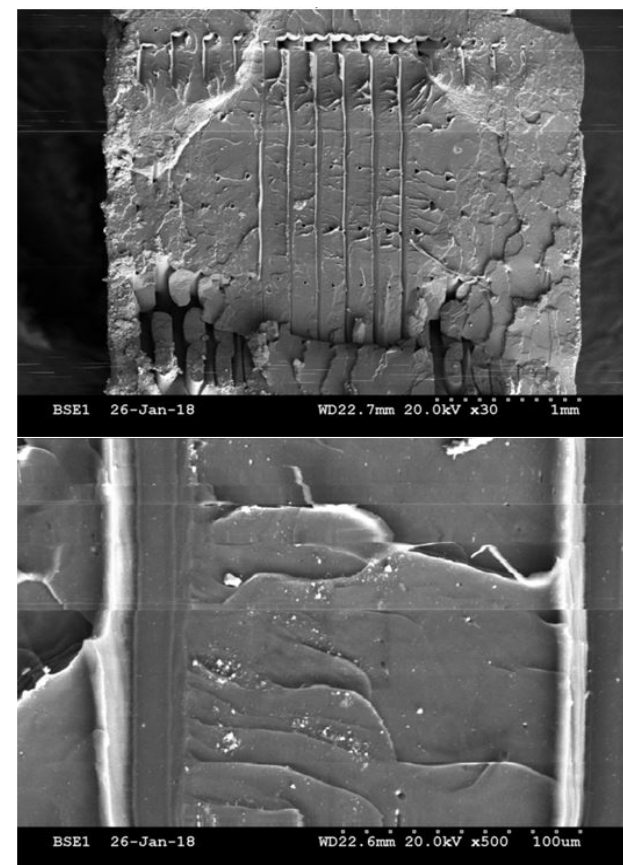

b)

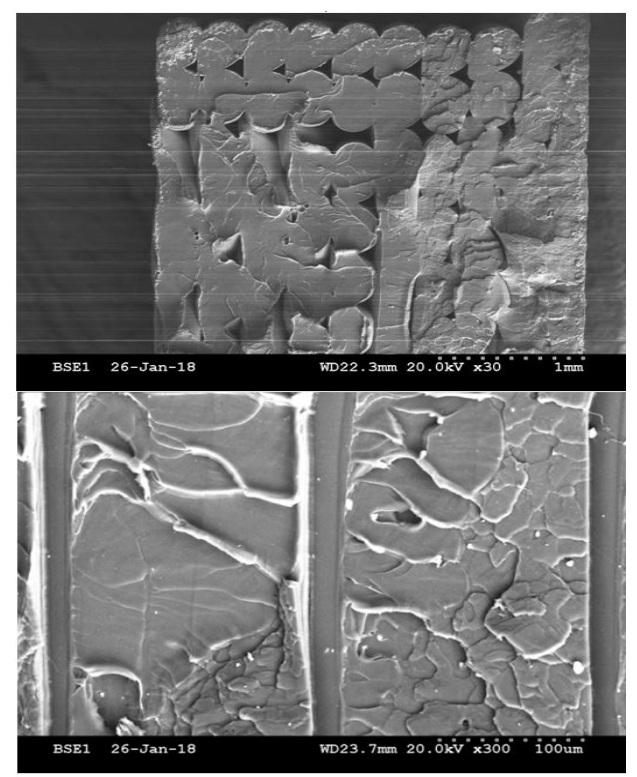

Fig. 12. Fracture surfaces (SEM) of specimens after bending, layer thickness: a) $0.1 \mathrm{~mm}$ and filling $100 \%$; b) $0.3 \mathrm{~mm}$ and filling $100 \%$ 


\subsection{Impact resistance testing}

The results of the Charpy test are shown in Figure 13. Impact resistance depends on the path of printing; higher values were recorded for material printed with a parallel path to the axis (series I) than with $\pm 45^{\circ}$ path angles (series II). Holes are observed on facture surfaces of Charpy specimens (Fig. 14) between filaments and layers. More holes and weaker joining are observed for printed material with $50 \%$ filling ratio (Figs. 14 a, b and Figs. 14 e, f). Better joining of the filaments and layers took place in samples with a path $\pm 45^{\circ}$ and $0^{\circ}$ and a $100 \%$ filling.

a)

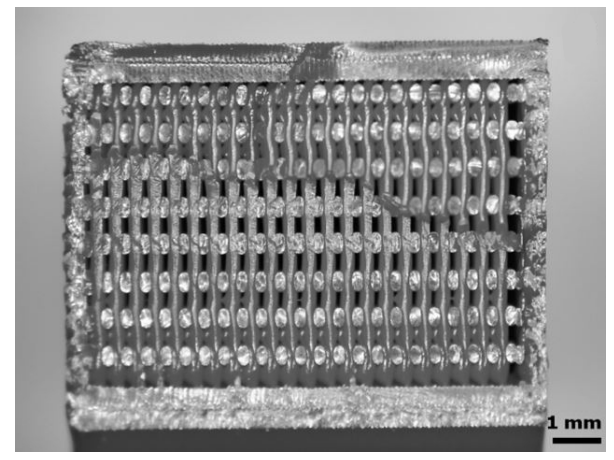

c)

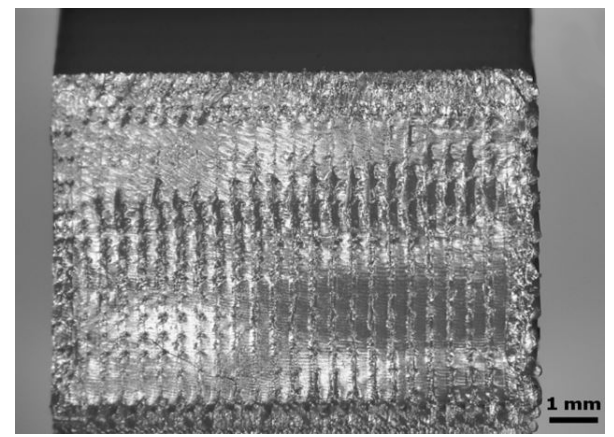

e)

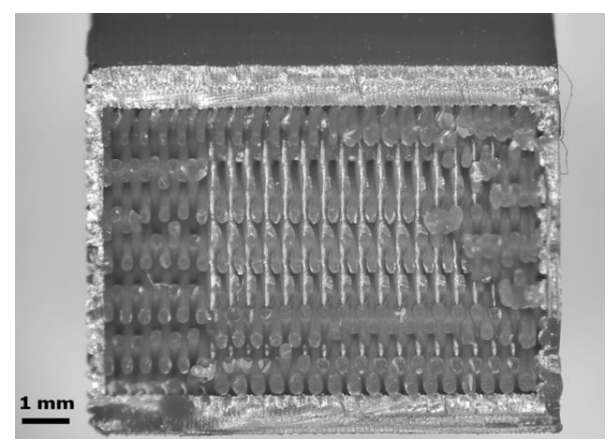

g)

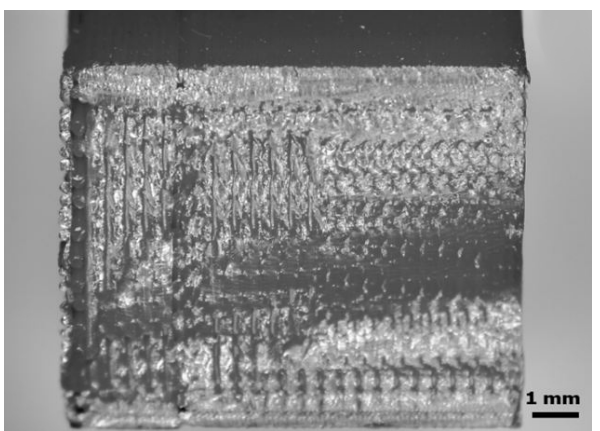

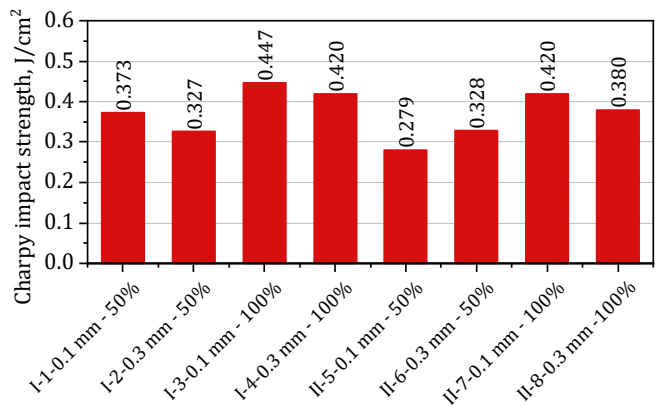

Fig. 13. Average impact resistance, for printed thicknesses 0.1 or $0.3 \mathrm{~mm}$ and filling 50 or $100 \%$ (legend: series, no. of set samples, layer thickness, filling, see Table 1)

b)

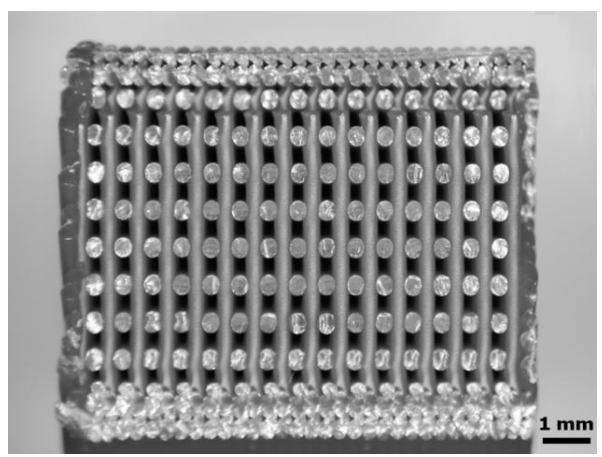

d)

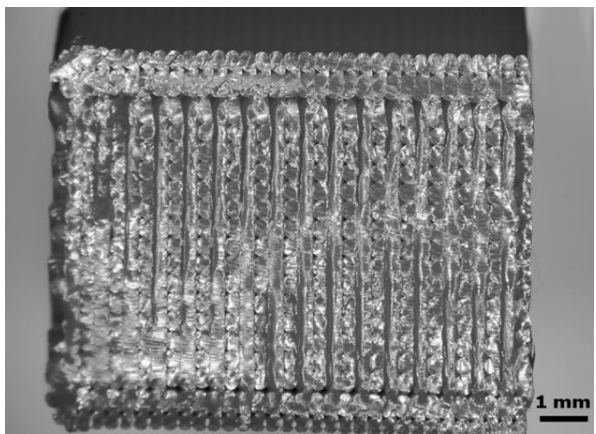

f)

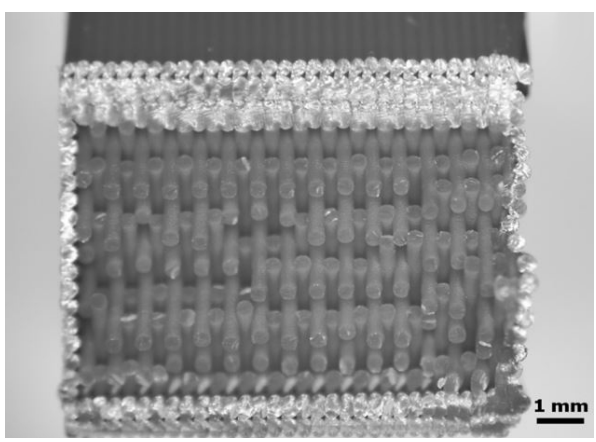

h)

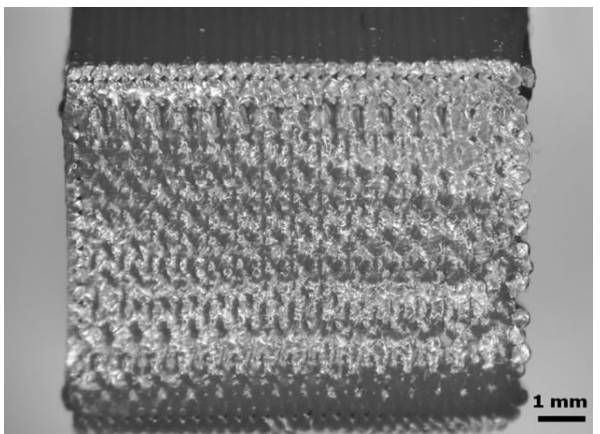

Fig. 14. Fracture surfaces of specimens after Charpy testing: a) I-1; b) I-2; c) I-3; d) I-4; e) II-5; f) II-6; g) II-7; h) II-8 (legend see Table 1) 


\section{DISCUSSION}

The density of printed materials depends on layer thickness, filling and architecture established by the printing temperature. To be noted are differences in printing, e.g. layer thickness and number of shell perimeters. The mean densities of printed samples were: series I- $1-0.82$, I-2 -0.79 , I-3 - 1.23, I-4 - 1.19 and series II-5 - 0.82, II-6 - 0.01, II-7 - 1.19, II-8 $-1.18 \mathrm{~g} / \mathrm{cm}^{3}$, i.e. smaller than the $1.24 \mathrm{~g} / \mathrm{cm}^{3}$ density of PLA filament produced by injection moulding. The relative density was is in the range $0.63-0.65$ for $50 \%$ and 0.94-0.98 for $100 \%$ filling. Fill density strongly influenced all the mechanical properties of the printed materials. The layer thickness and architecture have a smaller influence than filling by established printing parameters. Holes are a further factor influencing mechanical properties. The layered macrostructure, including holes, is shown in Figure 12 and in Figure 14 on the fractographs of bend specimens. Impact resistance of our printed PLA is comparable to that of moulded material $1.3-5.5 \mathrm{KJ} / \mathrm{m}^{2}[11]$.

Table 3 summarizes the mechanical properties of printed PLA, i.e. mean value and confidence interval with $a=0.05$ for the 3 elements population. More repeatable values of Young's modulus were for materials with the relative density $0.94-0.98$. Tensile stresses were about $40 \%$ higher for $100 \%$ filled printed material, comparable for material with a parallel and $\pm 45^{\circ}$ printed structure. Elongation depended on layer thickness, filling and structure. For parallel printed structure, layer thickness 0.1 and fillings 50 and $100 \%$, tensile elongation was $\sim 2.8 \%$ for both, and for layer thickness 0.3 it was $3.5 \%$ and $2.3 \%$, respectively. For printed parallel material structure, it was $3.2 \%$ and $2.5 \%$, and was higher $3.9 \%$ and $4.0 \%$ for material structure $\pm 45^{\circ}$.
All the strengths were, as is generally the case for polymers, in ascending order: compressive, flexural. The differences between tensile and compressive result from the nature of deformation mechanisms in polymers. For bend strength, there is the additional problem of the complex elastic-plastic stress distribution in a bending beam when the tensile and compressive yield stresses are unequal.

Only phenomenological correlations, e.g. with density and architecture, are presented. For additional aspects, the reader is referred to the discussions of Lanzottii et al. [7] and Grasso et al. [8], whose tensile results and those of Letcher and Waytashek [9], Anderson [10] and Ezeh and Susmel [12] are presented in a Table 4. This summarizes the strength properties of printed PLA in comparison with strength properties reported in [7-12].

It is clearly discernible that, when direct comparison can be made, Young's moduli reported by Lanzotti et al. [7] and Grasso et al. [8] are somewhat higher than now reported. UTS are slightly higher, but the small influence of infill orientation $(0 / 90$ and \pm 45$)$ and layer thickness of $0.1-0.3 \mathrm{~mm}$ is to be noted. Yield stress reported by Anderson [10] is comparable at $40 \mathrm{MPa}$ for layer thickness $0.4 \mathrm{~mm}$. UTS reported by Letcher and Waytashek [9], 58 and $64 \mathrm{MPa}$ for infill orientation 0 and \pm 45 , is higher than our values.

One interesting and perhaps fortuitous correlation relates to printed material with parallel infill and is connected with density and strength. For MIM, the PLA filament has $55 \mathrm{MPa}$ tensile strength and a yield strength of $45 \mathrm{MPa}$. Using the same scaling factor for density and strength, for 0.66 relative density, tensile and yield strengths evaluate to $36 \mathrm{MPa}$ and $30 \mathrm{MPa}$ respectively, and the measured values were $30 \mathrm{MPa}$ and $29 \mathrm{MPa}$. For 0.96 relative density evaluated strength and yield stresses of $53 \mathrm{MPa}$ and $43 \mathrm{MPa}$ are to be compared with experimental values of $47 \mathrm{MPa}$ and $45 \mathrm{MPa}$.

Table 4

Average tensile properties at room temperature

\begin{tabular}{|c|c|c|c|c|c|c|c|}
\hline \multirow[b]{2}{*}{ Results source } & \multicolumn{4}{|c|}{ Property } & \multicolumn{3}{|c|}{ Parameters } \\
\hline & $\begin{array}{c}E, \\
\text { GPa }\end{array}$ & $\begin{array}{l}\text { UTS, } \\
\text { MPa }\end{array}$ & $\begin{array}{c}Y S, \\
\text { MPa }\end{array}$ & $\begin{array}{c}\sigma_{b^{\prime}} \\
\mathrm{MPa}\end{array}$ & $\begin{array}{c}\text { fill density, } \\
\%\end{array}$ & $\begin{array}{c}\text { infill } \\
\text { orientation }\end{array}$ & $\begin{array}{l}\text { layer thickness, } \\
\text { mm }\end{array}$ \\
\hline \multirow{2}{*}{ Lanzotti [7] } & 3.4 & 49 & - & - & \multirow{2}{*}{$100^{*}$} & $0 / 90$ & 0.2 \\
\hline & 3.0 & 48 & - & & & \pm 45 & 0.15 \\
\hline \multirow{2}{*}{ Grasso [8] } & 2.2 & 45 & - & - & - & $0 / 90$ & 0.18 \\
\hline & 2.8 & 50 & - & - & - & \pm 45 & \\
\hline Letcher and & 3.33 & 58 & - & - & \multirow{2}{*}{$100^{*}$} & 0 & - \\
\hline Waytashek [9] & 3.49 & 64 & - & - & & \pm 45 & - \\
\hline $\begin{array}{l}\text { Anderson [10] } \\
\end{array}$ & 4.26 & - & 40 & - & - & - & 0.4 \\
\hline \multirow{2}{*}{$\begin{array}{l}\text { Ahmed and } \\
\text { Susmel [12] }\end{array}$} & 1.16 & 16 & 14 & - & 60 & 0 & 0.1 \\
\hline & 2.06 & 26 & 24 & - & 90 & 0 & 0.1 \\
\hline \multirow{8}{*}{ Current } & 1.6 & 30 & 23 & 68 & 63 & $0 / 90$ & 0.1 \\
\hline & 1.4 & 23 & 23 & 54 & 64 & $0 / 90$ & 0.3 \\
\hline & 2.5 & 47 & 45 & 102 & 94 & $0 / 90$ & 0.1 \\
\hline & 2.3 & 43 & 41 & 85 & 94 & $0 / 90$ & 0.3 \\
\hline & 1.5 & 28 & 27 & 63 & 65 & \pm 45 & 0.1 \\
\hline & 1.4 & 27 & 26 & 65 & 65 & \pm 45 & 0.3 \\
\hline & 2.2 & 42 & 40 & 77 & 98 & \pm 45 & 0.1 \\
\hline & 2.2 & 47 & 45 & 101 & 98 & \pm 45 & 0.3 \\
\hline
\end{tabular}

* printer parameter, not calculated for the sample 


\section{CONCLUSIONS}

Full mechanical characteristics (tensile, compression and bend strengths and impact resistance) of the printed PLA material are reported. The layered structure resulting from the filament polymer source and holes inside the layers produce material with an irregularly shaped macrostructure which influences its properties. The macrostructure changes probably occur as a result of the thermal influence on the starting polymer filament. These results shown possibility printing with a 0.3 , i.e. shorter printing time than $0.1 \mathrm{~mm}, 0.15 \mathrm{~mm}$ and $0.18 \mathrm{~mm}$ layer thicknesses also reported, without significant decrease in mechanical properties.

These results are comparable to those previously reported and show that reasonably good and reproducible mechanical properties are achievable with desktop [entry level] printers. It is interesting to note that the compressive strengths, the yield of 70-80 MPa and a UTS 113-120 MPa for the printed material with a fill density of $94-96 \%$ are comparable with those of aluminum.

\section{Acknowledgements}

The research was financed by the Ministry of Science and Higher Education (AGH - research subsidy no. 16.16.110.663, task 3).

\section{REFERENCES}

[1] Masood S.H. (2014). Advances in fused deposition modelling. In: Hashmi S., Batalha G.F., Van Tyne C.J. \& B. Yilbas (Eds.), Comprehensive Materials Processing. Elsevier.

[2] Masood S.H., Mau K. \& Song W.Q. (2010). Tensile properties of processed FDM polycarbonate material. Materials Science Forum, 654/656(1), 2556-2559, https://doi.org/10.4028/ www.scientific.net/MSF.654-656.2556
[3] A. Bellini \& Güçeri S. (2003). Mechanical characterization of parts fabricated using fused deposition modeling. Rapid Prototyping Journal, 9(4), 252-264.

[4] Novakova-Marcincinova L. \& Novak-Marcincin J. (2014). Testing ABS material tensile strength for fused deposition modeling rapid prototyping method. Advanced Materials Research, 912/914(1), 370-373, https://doi.org/10.4028/www.scientific.net/AMR.912-914.370

[5] Smiths W.C. \& Dean R.W. (2013). Structural characteristics of fused deposition modeling polycarbonate material. Polymer Testing, 32(8), 1306-1312, https://doi.org/10.1016/ j.polymertesting.2013.07.014

[6] Durgun I. \& Ertan R. (2014). Experimental investigation of FDM process for improvement of mechanical properties and production cost. Rapid Prototyping Journal, 20(3), 228-235, http://dx.doi.org/10.1108/RPJ-10-2012-0091

[7] Lanzotti A., Grasso M., Staiano G. \& Martorelli M. (2015) The impact of process parameters on mechanical properties of parts fabricated in PLA with an open-source 3-D printer. Rapid Prototyping Journal, 21(5), 604-617, https://doi. org/10.1108/RPJ-09-2014-0135

[8] Grasso M., Azzouz L., Ruiz-Hincapie P., Zarrelli M. \& Ren G. (2018). Effect of temperature on the mechanical properties of 3D-printed PLA tensile specimens. Rapid Prototyping Journal, 24 (8), 1337-1346, https://doi.org/10.1108/ RPJ-04-2017-0055

[9] Letcher T. \& Waytashek M. (2014). Material property testing on of 3D-printed specimen in PLA on entry-level 3D printer. Proceedings of the ASME 2014 International Mechanical Engineering Congress and Exposition. Volume 2A: Advanced Manufacturing. Montreal, November 14-20. ASME, https://doi. org/10.1115/IMECE2014-39379

[10] Anderson I. (2007). Mechanical Properties of Specimens 3D Printed with Virgin and Recycled Polylactic Acid. 3D Printing and Additive Manufacturing, 4(2), 110-114, https://doi. org/10.1089/3dp.2016.0054

[11] Polylactic Acid (PLA) Typical Properties, http://prode.me/ uploads/news/9a8c705752ed9f3279f0167013f574b0.pdf [accessed 26.04.2019].

[12] Ezeh O.H. \& Susmel L. (2019). Fatigue strength of additively manufactured polylactide (PLA): effect of raster angle and non-zero mean stresses. International Journal of Fatigue, 42(4), 883-904,https://doi.org/10.1111/ffe.12958 